\title{
Los primeros 1 de mayo en Cádiz como jornada obrera
}

MARCOS CORREA LOPEZ

En las páginas del artículo que aquí presentamos pretendemos acercar al lector una primera aproximación de los acontecimientos ocurridos en Cádiz los primeros años de la celebración del día 1 de Mayo. Para comenzar, permítasenos recordar en primera instancia las raíces de esta celebración.

Los orígenes de la celebración del Primero de Mayo como fecha eminentemente obrera hay que buscarlos en los Estados Unidos. En el IV Congreso de la American Federation of Labor, reunido en noviembre de 1884 en Chicago, se acordó, en vista de los fracasos habidos en las gestiones efectuadas ante los poderes públicos y los partidos políticos, para conseguir imponer la jornada de ocho horas, sin disminución de sueldo, en todos los oficios, establecer el 1 de Mayo de 1886 como fecha de una huelga general nacional que obligase a los patronos a acceder a esta pretensión. Los resultados en principio fueron alentadores: más de treinta mil obreros consiguieron su propósito con el simple anuncio de la medida, y en la jornada decretada hubo más de 5.000 huelgas y 300.000 huelguistas, consiguiéndose en algunos casos lo pretendido y en otros distintas mejoras.

Sin embargo, en Chicago, con un ambiente social sumamente enrarecido, el estallido de una bomba entre las filas de la policía y la posterior represión realizada por ésta produjeron un número de muertos elevado, aunque imposible de determinar. Como consecuencia de estos sucesos, la actuación policial se cebó en los más conspicuos dirigentes obreros radicales (con un añadido conflicto de xenofobia, puesto que éstos eran casi todos de origen y lengua alemana), celebrándose una farsa de juicio que terminó con ocho condenas de horca, que acabaron en una ejecución quíntuple el 11 de noviembre de 1887. Años más tarde, una investigación del nuevo gobernador de 
Illinois demostró el claro carácter teatral del juicio, rehabilitándose públicamente a los sentenciados.

En su congreso de Saint Louis, la A.F.L., reincidiendo en sus peticiones, volvió a convocar como jornada nacional para la consecución de las ocho horas el 1 de Mayo, de 1890 en este caso. La resolución fue ratificada en el Congreso de Boston de 1889. Esto, como se comprenderá, resulta de importancia fundamental para la historia del Primero de Mayo en el mundo, pero no menos lo es, y sí quizás mucho más, para el concreto caso de la corriente anarquista en el movimiento obrero, el hecho de los cinco ajusticiamientos, los "crímenes legales" de los "Mártires de Chicago", apelativo por el que serán conocidos universalmente en el Olimpo de los héroes libertarios.

El salto de la fecha del Primero de Mayo a Europa se debe a la iniciativa del congreso internacional celebrado por los socialistas de afinidades marxistas en París, en julio de 1889, en el que estuvo presente Pablo Iglesias. En él se acuerda organizar una manifestación internacional en un determinado día, para que los trabajadores de todo el mundo aboquen a los poderes públicos a reducir por ley la jornada de trabajo a ocho horas, como asunto principal, y a adoptar otra serie de propuestas de legislación social y laboral. La determinación del día 1 de Mayo en concreto obedece al conocimiento de que previamente ya lo habían adoptado los trabajadores norteamericanos, no cabiendo por tanto ninguna duda sobre la paternidad de la iniciativa. Pero, eso sí, queremos resaltar la diferencia en la vía que se elige para alcanzar el fin deseado: mientras que los obreros ultramarinos piensan dirigir sus reivindicaciones directamente a sus patronos, una vez desengañados de la alternativa de elevar peticiones a la autoridad política, los socialistas europeos optan por pedir a los poderes públicos su comprensión y la asunción de sus determinaciones (1).

Esta división sobre los medios a adoptar para conseguir los resultados ansiados se reproduce fielmente en el movimiento obrero español. Los socialistas, con su organización sindical recién fundada,

(1) Para la relación de estos acontecimientos hemos seguido la obra de Dommanget, M., Historia del 1ํ de Mayo, Laia, Barcelona, 1976. También un resumen de la misma se puede ver en el artículo de Lucía Rivas Lara "El primero de Mayo, jornada obrera, 1890-1930", en Estudios de Historia Social, no 38-39, Madrid, 1986, pp. 271-337, o lo que es lo mismo, en su libro Historia del $1^{\circ}$ de Mayo en España desde 1900 basta la Segunda República, UNED. Madrid, 1987. Para los acontecimientos de Chicago en concreto, remitimos al lector a Yellen, S., "Los partidarios americanos de la "Propaganda por los hechos"", en la compilación de Horowitz, I. L., Los anarquistas, Alianza. Madrid, 1979, vol. 2, pp. 69-92. 
siguen los acuerdos adoptados en París y pretenderán que de sus federaciones se destaquen comisiones que eleven a los poderes políticos, locales o provinciales, las peticiones de los trabajadores. Además, como buena muestra de que los socialistas se acercaban a ese día con más temor que esperanza, se puede argumentar el acuerdo tomado en el sentido de cambiar la fecha de la celebración del 1 al 4 de mayo, para que así coincidiese con domingo. Su explicación es la que sigue:

"Dado que en nuestro país las organizaciones obreras son relativamente escasas, y por lo mismo la masa proletaria se halla más diseminada o influida por dominio patronal, verificar las reuniones y manifestaciones en el dia de labor; es exponerse a sufrir un fracaso o por lo menos quitar a aquellas partes de su importancia. No asi en día festivo" (2).

En este mismo sentido se debe entender su prevención ante cualquier declaración de huelga, y la preferencia por conmemorar la jornada simplemente con mítines y manifestaciones. Sin embargo, no se puede evitar hacer la observación de que, precisamente en el lugar donde los socialistas consiguieron arrastrar tras sí a los obreros de forma más inequívoca, si bien es cierto que con cambio de fecha incluido, fue alli donde menos se siguieron las directrices moderadas, y la movilización producida terminó acercándose mucho más a los parámetros de actuación mantenidos por el sindicalismo de raíz anarquista. Nos estamos refiriendo, claro está, a Vizcaya (3).

Por lo que respecta a la vertiente anarquista del movimiento obrero español, debemos comenzar por dejar muy clara su oposición, en primer lugar, a la idea de sus compañeros socialistas de elevar peticiones a las autoridades políticas, y consecuentemente con su habitual práctica de la acción directa, opinan que cualquier mejora en la situación de la clase proletaria debe conseguirse mediante la propia actuación de ésta, sin intermediarios, frente a la clase capitalista, en aplica-

(2) "Manifestación Obrera de Mayo", en El socialista,11-IV-1890, citado en Baladrón, B., "La fiesta de trabajo en España: los primeros años", en Estudios de Historia Social, № 38-39. Madrid, 1986, pp. 121-170. Texto en el que basamos estas indicaciones sobre la recepción a nivel estatal del Primero de Mayo.

(3) Sobre este asunto en concreto ver Miralles, R., "La Gran Huelga Minera de 1890. En los Orígenes del Movimiento Obrero en el País Vasco", en Historia Contemporánea, № 3. Servicio Editorial de la Universidad del País Vasco, Bilbao, 1990; Olabarri, I., Relaciones laborales en Vizcaya, 1890-1936, Durango, 1978; y especialmente Fusi, J.P., Politica obrera en el País Vasco (1880-1923), Turner. Madrid, 1975. 
ción estricta de la lucha de clases. Por otra parte, también en absoluta armonía con su tradicional relación dialéctica entre fin último y praxis cotidiana, no dejan de insistir en que el movimiento por la consecución de la jornada de ocho horas no es más que un paso, un escalón de la lucha por eliminar la sociedad capitalista. No podemos resistir la tentación de reflejar aquí un texto que lo expone claramente:

"No bay que bacerse ilusiones: no bay razón para sostener como un ideal definitivo de la clase trabajadora la conquista de las ocho boras. Sea cualquiera el resultado de este movimiento, conviene repetir una vez más que lo que los trabajadores quieren es poner término al régimen de salario.

"(...) Las ocho horas es un grito de guerra; mejor dicho, un episodio de guerra; pero no el objetivo de la guerra.

"(...) No pueden establecerse legislativa, ni gubernamentalmente las ocbo horas en una nación, sería necesario una legislación internacional sostenida con energía, con buena fé. $Y$ ¿hay quien crea a los gobiernos capaces de entender para esto en bien de los trabajadores, cuando se ve que no ban podido, ni querido lograrlo respecto de los tratados comerciales en que se trata de intereses de la burgesia?

"Las ocho boras al ser un punto de coincidencia del proletariado bay que lucbar por ellas aunque no sea el fin.

"A las ocbo boras, pues, en bonra de la nación obrera internacional!

"A las ocho horas como manifestación de nuestra fuerza!

"iA las ocbo boras como limitación del poder y de la soberbia de nuestros explotadores!

"A las ocbo boras como medio precursor de nuestra emancipación económico-social!" (4).

Centrándonos ahora en Cádiz, debemos iniciar nuestro relato recordando que en 1885 Salvochea regresa a Cádiz tras sus años de presidio. Cuando por fin vuelve a su ciudad natal, converso ahora al anarquismo en su vertiente comunista, funda el periódico El Socialismo; con él pretende reanimar el movimiento obrero en la provincia, que prácticamente había desaparecido tras la represión seguida por las autoridades gracias a los sucesos de la Mano Negra. Y realmente se

(4) El Productor, 30-IV-1890, citado por Baladron, Art.Cit., p. 126. 
produce un cierto renacimiento, que se traduce en la constitución formal de grupos de trabajadores (5). El anuncio de la celebración del Primero de Mayo por los proletarios de todo el mundo insufla nuevos bríos al movimiento, y "sin lugar a dudas fue en la provincia de Cádiz, donde con mayor ahínco los anarquistas, con Salvochea a la cabeza, se esforzaron en crear un clima favorable a esta jornada. Las páginas del periódico El Socialista [sic] servirán para que este antiguo federalista, convertido al anarquismo, inicie la gran propaganda de este día" (6).

Así preparado el ambiente en la ciudad, a la llegada del día señalado, las autoridades hicieron gala de una serie de prevenciones, en la sospecha de una eventual alteración de relieve del orden público, eso sí, sin impedir la realización de los actos previstos, en concordancia con la actitud benevolente del Gobierno Sagasta. Las medidas adoptadas se centran en la protección de los edificios públicos: cierre del Ayuntamiento y custodia del mismo por fuerzas del ejército, protección del Gobierno Civil por la Guardia Civil, etc. Al mismo tiempo, otros servicios de guarda del orden público se apostaron a lo largo del recorrido previsto de la manifestación obrera (7).

Los obreros gaditanos, siguiendo la línea de actuación de todos los anarquistas españoles, optaron también por efectuar la manifestación el mismo día 1, en vez de trasladarla al domingo cuatro, como pretendían los socialistas, y además hacerlo con una manifestación por las calles de la ciudad. Este hecho permite a Jacques Maurice referirse a que "la movilización popular permitió reconquistar la calle, prohibida desde los lejanos tiempos de la Primera República" (8).

La demostración obrera comenzó con una concentración en la plaza de Las Barquillas de Lope, "situé dans le quartier pauvre" (9).

(5) ROSETTY, J., Guía de Cádiz. Cádiz, 1891. Al parecer, a finales del mes de febrero de 1890 , existian en la ciudad 48 sociedades "de recreo, literarias, de obreros ó protectoras de éstos". Ibídem, p. 108.

(6) BALADRON, B., Art. cit., p. 159. Evidentemente, quiere decir El Socialismo.

(7) Ibidem. La autora basa su descripción exclusivamente en la información dada por El Productor de 4-V-1890, aunque por error tipográfico se indica el mes de abril.

(8) MAURICE, J., El anarquismo andaluz, Crítica. Barcelona, 1990, p. 161.

(9) Tomado de uno de los informes enviados por el cónsul francés en Cádiz, De Laigue, conservados en los Archivos del Ministerio de Asuntos Exteriores de Francia (en adelante A.M.A.E.F.), Serie Correspondance Politique des Consuls (en adelante C.P.C.), Cadix, Vol. 98, 2-V-1890. Está será una de las fuentes principales de nuestro trabajo. Señalaremos que tanto en este original como en el artículo citado de Baladron, el lugar es equivocadamente llamado Barquillas de López. 
Ante ella, tomaron la palabra Ponce y Salvochea (10). De Laigue, cónsul francés en Cádiz, nos indica que el primero basó su disertación en preconizar "l“Union des travailleurs et la journée de huit heures" (11). Respecto al segundo, su explicación es más detallada y, entrecomilladamente, nos ofrece los siguientes párrafos:

"La disminution du travail, l'aumentation de salaires, la solidarité ouvrière, amèneront le triomphe de la révolution sociale. L'ouvrier, esclave blanc, est plus pressuré que l'esclave noir. Aussi doit-il préférer mourir sur le pavé, une balle au coeur, que de crever de faim dans sa demeure. Les cérémoines religieuses sont des momeries et si le peuple s'est rendu enfacile aux récentes processions de la semaine sante, a été uniquement por voir "la tête" de la femme qui "faisait" sante Verónique".

"Pour écraser le prolétaire, la bourgoisie s'appuie sur trois leviers: le prêtre, le magistrat, le soldat. Mais le prête dit sa messe pour nuire et ne songe pas à la gloire du ciel. Quant à la magistrature, le peuple sait bien que le pouvoir étant sien qui l'exerce, l'usurpe et l'on comprend ce que parler veut dire. Quant à l'armée, quelle invraisemblance de noir les fils du peuple servir d'instrument contre le peuple. Un jour viendra oú canons et fusils se retourneront contre les bourgeois. Le triomphe de l'anarchie et de la Révolution sociale approche: aussi les bourgeois tremblent en voyant l'importante démostration qui remplit le monde se ses échec.

"oui, communisme et anarchie sont sur la voie du triomphe. Dans le socialisme point de man̂tre tous égaux. Ouvriers, pesez et la balance de la justice penchera de votre côté".

(10) Según Fernando de Puelles, en Fernín Salvocbea República y Anarquismo, edición del autor, Sevilla, 1984, p. 160, habló Blas, secretario del Centro Obrero. Hemos de decir que al tal Blas, sólo lo menciona este autor, y en esta única ocasión, siéndonos por lo demás desconocido. Por otro lado, tenemos que negar la existencia del cargo señalado, puesto que el Centro Obrero en estas fechas no había sido aún creado; más adelante daremos noticia de su fundación. En cuanto a la obra citada, nos vemos en la obligación de señalar su absoluta falta de fiabilidad, puesto que no se da en toda ella una sola referencia respecto al origen de las fuentes en las que se basa lo escrito. Es realmente de lamentar que la reciente trágica muerte del autor haya impedido el poder ver esa "edición de mayores dimensiones", con aparato erudito, apéndices y bibliografias que nos había prometido en la introducción (p. 12).

(11) Todas las afirmaciones del cónsul francés sobre este día se localizan en el documento más arriba señalado. 
A continuación, ofició como orador cierto Suárez, que vino a decir:

"Faisons disparaître de la langue les mots "le tien" et "le mien" et n'ayans plus que le possessif commun "le nôtre". Armée, magistrature, clergé, soutiennent la bourgeios. Celle-ci revendique pour elle tous les droits, et quand le proletaire en appelle du burgeois à ce qu'on est convenu de qualifier "loi", on le jette dans d'inmondes cachats et la fête bourgeois en arrive même à lui triturer la garge sur l'echafand. Les socialistes neulent agir par la seul force de la raison et faire jusqu'á là lie le calice de la patience; mais si la force de la raison est impuissante, ont recourra certainement à la raisson de la force".

Tras estos discursos, los obreros, que se habían congregado en número aproximado a los 3.000 (12), iniciaron la manifestación por la ciudad, en absoluto orden, hasta el punto que la Guía de Cádiz no da mayor importancia, gracias a este hecho, a la celebración del día, y la despacha en muy escasas líneas, prácticamente limitándose a destacar que "una manifestación del partido socialista recorrió el primero de este mes la mayor parte de las calles y plazas de esta ciudad, sin que en el vecindario se notase que este acto, causara el menor síntoma de intranquilidad" (13). Al frente de la marcha los trabajadores portaban una enseña roja con el lema "Viva la jornada de ocho horas" en letras negras. Después de hacer su recorrido, la manifestación terminó en el mismo punto en donde se había iniciado y, reagrupándose nuevamente, los discursos recomenzaron otra vez. En esta ocasión, inició el turno Pedro Canales, quien afirmó, según la versión del despacho consular, que el pueblo al fin había cumplido sus derechos y los afirmaba, siguiendo:

"Fidéle aux traditions du passé, Cadix s'associe avec vaillance mais modération, aux grandes revendications du monde. Sans doute l'emancipation de l'ouvrier ne s'aperéra pas de jour ou lendemain, mais nous prenous date pour faire valoir nos droits, car

(12) Según Baladrón, éste es el número que se da en la crónica de El Imparcial, mientras que El Productor (periódico anarquista, no lo olvidemos), lo eleva hasta 6.000, Art. Cit., p. 160. La coincidencia en la cantidad, junto al desapasionamiento de las dos fuentes que la dan, nos hace inclinar por su objetividad.

(13) ROSETTY, J., Op. Cit., p. 110. 
il est injuste que les uns aient asént tant et les autres rien. Qui produit tant a droit á tant. A bas les parasites qui se gargent su travail d'autrui".

Fueron estas palabras recibidas con evidentes y señaladas muestras de aprobación por todos los asistentes, para a continuación Salvochea ocupar por segunda vez el papel de orador, principiando su intervención con una frase afortunada: "hoy habéis perdido el salario, pero hemos ganado la jornada". Para luego continuar:

"Iusq'ici le sang ouvrier sus l'échafand n'a fait qu'exacerber le désir de secour le joug qui opprime le necessiteux: et, en croyant entrainer la revolution sociale, on en a précipité l'écbeance. Aujourd'bui, nous préludons aux grands changements sociaux".

Según Salvochea, la nueva era que abrirán traerá la igualdad "pour tous", que acabará con el hecho de que:

"les pouvres meurent de jaim et le riches d'indigestion. Le socialisme c'est l'ordre qui établit le véritsable équilibre entre les bommes.

"L'actuel état des choses est une véritable dérisson, car on meurt d'inanition devant les magasins regangeant de comestibles et l'on meurt de froid á la porte des boutiques remplier de chaudes étoffes".

Acabando con un "Viva el Comunismo y la Anarquía" fue Salvochea fuertemente aplaudido por los congregados (14).

Según la visión que de las declaraciones arriba por primera vez trascritas da Maurice, "en los discursos pronunciados para la ocasión ya aparecieron algunos matices. Los compañeros de Salvochea hacian hincapié en el ejercicio de los derechos de los trabajadores: asociación y huelga; Salvochea, por su parte, consideraba el paro masivo en el trabajo como el preludio de "grandes cambios sociales" (15). Hemos visto que esto último es completamente cierto, mas, sin embargo, nos permitimos disentir de lo que le antecede. En primer lugar, porque, en una misma sesión, es bastante lógico que los diferentes oradores toquen diversos aspectos y no se centren todos en lo mismo, aunque sólo sea por razones didácticas y propagandísticas. Por otro lado hemos podido

(14) Todo lo anterior en A.M.A.E.F., ya citado.

(15) MAURICE, J., Op. Cit., p. 161. El autor cita a pie de página la misma fuente que nosotros hemos manejado. 
apreciar que el discurso de Suárez se asemeja bastante a la primera intervención de Salvochea y parece poco "sindical", que es, da la impresión, lo que Maurice pretende oponer a lo puramente "revolucionario", que estaría representado por el líder del Cantón.

Siguiendo con el contenido de los discursos, podemos señalar que las alusiones al frio, al hambre y a la pobreza no se corresponden a un único interés literario y retórico. Por el contrario, parece que la situación económico-social de la ciudad de Cádiz en esos añós se corresponde con un período de auténtica crisis, interesando en el asunto a los grupos sociales más conservadores. Así, por ejemplo, el 25 de mayo se demuestra la preocupación de la Iglesia gaditana por esta materia mediante la lectura de una Carta pastoral del Obispo en todas las iglesias "sobre eficaz remedio que pueda aplicarse al grave mal del pauperismo" (16). No queda circunscrita la atención prestada al problema por el Obispo y las clases acomodadas a esta Carta, sino que también intervienen prácticamente. Pondremos tan sólo dos ejemplos de ello ocurridos en el mismo mes, en septiembre. El primero se refiere a la inaguración por la máxima autoridad eclesiástica de la ciudad de una 'fonda popular", en el barrio de La Palma, "en la que por una insignificante cantidad, se facilita alimento sano y nutritivo a los menesterosos". Tal realización se debe "a la iniciativa y cooperación" del marqués de Santo Domingo de Guzmán (17).

En el otro caso es la Sociedad Casino Gaditana la que actúa, invitando a los artistas que en aquellas fechas trabajaban en el Teatro Principal, a dar una representación en sus salones, cuya recaudación sería destinada "á socorrer á los necesitados". En esa actuación, celebrada el día 1 de septiembre, se recolectó un total de 3.375 pesetas, lo que hizo posible que "fueran muchos los pobres que disfrutaron del producto de ese concierto" (18).

Volviendo a centrarnos ahora en el devenir concreto del movimiento obrero en sí, recogemos una frase de Maurice en la que resume el contenido de un artículo de El Socialismo publicado en un número algunas semanas posterior a la conmemoración del Primero de Mayo; dice así: "La importancia de la huelga se debía menos a sus resultados que a su propia existencia, lo que podía suponer como inteligencia previa de los "productores" (19). Efectivamente, da la

(16) ROSETTY, J., Op. Cit., p. 111.

(17) Ibídem., pp. 114-115.

(18) Ibidem., p. 114.

(19) MAURICE, J., Op. Cit., p. 161. Cita como referencia El Socialismo, 16-VI-1890. 
impresión de que esto es así, y que como resultado de esa primera inteligencia, se abrió la posibilidad de un mayor acuerdo y solidaridad en el seno de la clase obrera gaditana, pues en fechas no muy lejanas, concretamente el 17 de agosto de ese mismo año, en el Circo-teatro se celebra una reunión de trabajadores con un muy principal punto en su orden del día: la proposición "de constituirse en un local amplio que se denominara "Centro Obrero", y al mismo tiempo aconsejar la unión, como fácil medio para que la clase se emancipara, base fundamental de la manifestación que celebraron en primero de Mayo" (20). Se puede asegurar, en consecuencia, que la conmemoración señalada tuvo, realmente, consecuencias prácticas positivas en la situación, al menos política, de los trabajadores de la ciudad: el resurgir del movimiento asociativo, tan férreamente vigilado hasta entonces en la provincia tras los sucesos de la Mano Negra, a los que hemos visto referirse en un par de ocasiones (al hablar de l'echafand) en los discursos del día uno de Mayo.

En conjunto, podemos asegurar que el Primero de Mayo de 1890 como jornada obrera, alcanzó en España unas repercusiones que ni el más optimista de los dirigentes de los trabajadores podía esperar. De forma que los socialistas ya en el mes de agosto demostraron un cierto interés por su continuidad (eso sí, siempre que se celebrase a nivel internacional). Además, su mayor preocupación se centrará en evitar que en ese día se declaren huelgas generales. Con la idea de oponerse a las mismas, acude Pablo Iglesias al Congreso Amplio (responde su nombre a la idea de recoger en el mismo todas las tendencias obreras) celebrado en Madrid en marzo de 1891, donde, empero, sus recomendaciones serán desantendidas. Impondránse, entonces, las opiniones anarquistas de buscar la obtención de la jornada de ocho horas mediante la lucha más puramente sindical y laboral, exigiéndola, por medio de la huelga, a los patronos, y desentendiéndose de cualquier tipo de petición al poder político (21). Mas este año las circunstancias de la vida parlamentaria y gubernamental no iban precisamente a acompañar estas previsiones de actuación: la llegada de Cánovas al poder, desplazando al más conciliador Sagasta, impone una línea de gran intransigencia en lo que respecta a permitir manifestaciones, huelgas, etc., prohibiendo explícitamente cualquier demostración en la vía pública.

(20) ROSETTY, J., Op. Cit., p. 114.

(21) BALADRON, B., Art, Cit., p. 171 y Diaz del Moral. J., Historia de las agitaciones campesinas andaluzas, Alianza. Madrid, 1979, p.131. 
Y precisamente en relación con este últmo aspecto encontramos en la prensa gaditana la primera noticia relacionada con la celebración del Primero de Mayo del año de 1891: la transcripción, el día 20 de abril, de lo aparecido, en torno a esas fechas, en la Gaceta de Madrid sobre manifestaciones y mítines (22).

La tensión ciudadana que favorece la cercanía de la jornada del 1 de Mayo va a saltar el día 24 de abril, cuando la detención de un individuo, detención de la que se desconoce el motivo, va a provocar un pequeño motín en la plaza de San Juan de Dios, lugar donde se ubica el Ayuntamiento, en el que se calcula participaron alrededor de 1.000 personas que reclamaban la liberación del arrestado. El suceso, iniciado a las ocho de la tarde, se prolongó hasta más de las once. Esto hace que se empiece a tomar en serio la adopción de medidas preventivas ante la inminencia de la jornada por las ocho horas, y se comience a adiestrar a soldados en los trabajos de mantenimiento de la fábrica de gas, tomada ya militarmente (23).

Dos dias más tarde, el 26 de abril, se celebra en el "Círculo Obrero" (24) una reunión para discutir sobre la actitud a adoptar por los obreros el 1 de Mayo. A esta reunión las fuentes indican que asistieron más de 3.000 trabajadores, por lo que no nos debe extrañar que se afirme que "salones, corredores, patio, todo estaba lleno de gente" (25). Durante el acto varios oradores tomaron la palabra, entre ellos Salvochea, García, Ponce, Espinosa, Villar y Mesa; todos los discursos se orientaron primordialmente a "encarecer la necesidad de la pronta emancipación del proletariado, procurando concluir con las injusticias de la burguesía" (26). A propuesta de Salvochea, García y Ponce, se aprobó la resolución de, "quiera no el gobierno" (27), o "malgré les tyranos" (28), según la versión, celebrar una manifestación, citándose a las doce del mediodía en la plaza de San Antonio. Además, a partir de ese momento, se declararía la huelga general, hasta la consecución de la jornada de ocho horas, decidiéndose todo esto entre fervientes aplausos y terminando con vivas al comunismo y la anarquía iniciados por Salvochea y coreados entusiásticamente por los asistentes,

(22) Diario de Cádiz, 20-IV-1891.

(23) A.M.A.E.F., C.P.C., Cadix, Vol. 99, 25-IV-1891.

(24) Ibidem., 27-IV-1891.

(25) Ibídem, y Diario de Cádiz, 27-IV-1891. Baladron, en su artículo citado, utilizando como fuente El Imparcial, ofrece la cifra, aún mayor, de 5.000 asistentes.

(26) Diario de Cádiz, 27-IV-1891.

(27) Ibidem.

(28) A.M.A.E.F., C.P.C., Cadix, vol. 99, 27-IV-1891. 
concluyendo el acto, que había comenzado a la siete de la tarde, sobre las diez de la noche. El cónsul francés no deja de ofrecer en su comunicado una reflexión acertada acerca del lugar elegido para la concentración: mientras que el año anterior se había optado por un punto situado en una zona obrera, en esta ocasión y ante la prohibición de manifestarse, se prefiere hacerlo, precisamente, en un emplazamiento "situé au centre du quartier riche", lo que demuestra el grado de confianza en sí mismos de los proletarios, así como un cierto ánimo de provocación, o al menos de indiferencia por sus órdenes, hacia las autoridades.

Por el resto de la provincia también se inician los rumores sobre posibles actividades obreras. Por ejemplo, se dice que en La Línea se proyecta plantear huelga por los trabajadores de los depósitos de carbones de Gibraltar, que son parte muy importante de la población fronteriza. Además, de Medina Sidonia, donde el día 27 había estado el Jefe de la Guardia Civil en la provincia, señor Sos, entre las clases acomodadas corre la especie de que el 1 los obreros radicales se dedicarían una hora al degüello, dos al saqueo y tres a "toda concupiscencia posible" (29). En la misma fuente se nos comunica que siguen las medidas gubernamentales para enfrentarse a la jornada obrera, concentrando a la Guardia Civil de a pie en Cádiz y a la de a caballo en Arcos, así como se advierte que el gobernador fiscalizará todos los telegramas que se dirijan a la prensa de Madrid, tanto por sus corresponsales como por cualquier otra persona.

Por otro informe del cónsul de Francia, nos podemos enterar de que algunas familias salen de la ciudad hacia el campo, según ellas dicen, para disfrutar "de la campagne printaniére", aunque al diplomático no le caben dudas sobre sus auténticas motivaciones. Más importante información es la que se refiere a Salvochea, a quien el gobernador civil, el señor Castellarnau, hizo llamar para procurar desistiese de celebrar la manifestación, a lo que aquél le contestó: "dusséje être seul je descendrai daus la rue le Primiere Mai". Ante esto, la máxima autoridad provincial consiguió un mandamiento judicial para detenerlo a él, a Ponce y a García, basándose en los discursos por ellos pronunciados en la reunión obrera; los arrestos se produjeron el día 29, a las once y treinta de la noche (30).

(29) Diario de Cádiz, 28-IV-1891.

(30) A.M.A.E.F., C.P.C., Cadix, Vol. 99, 30-IV-1891. 
Como consecuencia de las detenciones, gran número de trabajadores se concentraron en las inmediaciones del Centro Obrero, y se reunían numerosos grupos por las calles más o menos cercanas, llegando a improvisarse un mitin, acordándose seguir con los planes de la manifestación y asimismo destacar una comisión que fuese hasta el Gobierno Civil a reclamar la libertad para los detenidos. Así se hizo, llegándose una representación de cinco obreros ante el gobernador, quien les comunicó que los presos estaban a disposición del Juzgado, por lo que él carecía de competencias para tomar ninguna resolución.

Para lo que sí tenía atribuciones el gobernador era para cerrar el Centro Obrero (lugar que, según explica el cónsul francés, al gobernador le parece un "foyer de corruption et d'excitation á la révolte") (31), como así se hizo provisionalmente, mientras el Juzgado era informado (no podemos omitir que, en el interior del Centro, vivían varias familias), lo que ocurrió el día 30, fecha en que también era detenido el francés Fernando Paulet, también en relación a los discursos pronunciados el 26 (32).

Mientras todos estos hechos ocurrían, las distintas profesiones se planteaban las reclamaciones a exigir en la cercana jornada obrera; así los pintores pedían a sus patronos una rápida contestación a su pretensión de acceder con carácter inmediato a la jornada de ocho horas, petición efectivamente conteștada con celeridad pero en sentido negativo. A su vez, los panaderos, dando un plazo de veinticuatro horas a los dueños de las industrias, intentan imponer una serie de condiciones relacionadas con los sueldos, el número de obreros imprescindibles para elaborar el pan, según la cantidad que se quiera producir, horario laboral, inexistencia de horas extras, etc.

Igualmente se incrementa la toma de medidas en previsión de un amplio conflicto, por las autoridades, y, junto al definitivo acantonamiento de tropas en la fábrica de gas. Se dispone el acampamiento de efectivos en las inmediaciones del Astillero, para evitar coacciones contra quienes deseen acudir al trabajo, además de procederse a guardar las llaves de la caja de caudales del Ayuntamiento y haberse ya sacrificado en el Matadero reses suficientes para dos días. También en otros lugares se imponen las precauciones. En San Fernando, por ejemplo, ante la previsible actitud huelguística de panaderos, zapateros y salineros, se ordena el acuartelamiento de toda la Infantería de

(31) Ibidem., 1-V-1891.

(32) Diario de Cádiz, 1-V-1891. 
Marina, que estará "sobre las armas", así como la presencia de un retén de este cuerpo en el Ayuntamiento, al tiempo que una brigada se encargará de la fabricación de pan si éste llegase a faltar (33).

Algunas industrias también tomaron sus medidas por cuenta propia. Podemos citar en tal sentido los casos de la fábrica de tabacos y la Compañía Trasatlántica, las que anunciaron para el día 1 que aquel que "ne presenterait pas aux ateliers aujourd'hui serait (...) congédié" (34).

Por fin, llegada la madrugada del día uno se observaba un amplio despliegue de efectivos de los cuerpos de seguridad, que ya durante toda la noche habían patrullado en grupos de tres por toda la ciudad (35). A las cinco de la madrugada, hora en que debía comenzar el embarque de los obreros de la Trasatlántica en el dique de la Compañía, había allí concentradas varias patrullas de ocho guardias civiles, otros grupos de carabineros y también de agentes de orden público, estando presentes además sus respectivos mandos: el teniente de carabineros, el jefe de la Guardia Civil y el de Orden Público. Por todos los puestos del muelle se encontraba repartida otra sección de guardias civiles y en la estación un contigente de 23 artilleros se encargaba de guardarla. En cuanto a los trabajadores de la Compañía, se destaca la ausencia de un gran número de ellos, sobre todo, al parecer, caldereros, carpinteros y pintores, que, agrupados en las tabernas cercanas, observan el embarque de los compañeros sin atreverse a ejercer ningún tipo de coacciones. Respecto a los astilleros Vea-Murguía, sabemos que dejaron libertad a sus obreros para acudir o no. La afirmación de que "han concurrido muchos" que aparece en una de la fuentes que utilizamos, nos parece tan poco digna de crédito como la aseveración idéntica que se hace para el caso de las obras municipales (36), puesto que el de los albañiles será uno de los oficios en los que más importancia tendrá el paro, y prácticamente el último en el que habrá piquetes para incitar a abandonar el trabajo a los pocos que acudieron a la faena (37), y holgar en favor de la jornada de ocho horas, lo que se conseguirá rápidamente en lo que se refiere a las obras de reparaciones en la iglesia de San Francisco, cuando los obreros manifiesten al Obispo su intención de no trabajar hasta lograr ese horario, petición inmediatamente concedida por el prelado, respondiendo a este gesto los trabajadores con el recomienzo de la labor.

\section{(33) Ibídem.}

(34) A.M.A.E.F., C.P.C., Cadix, Vol. 99, 1-V-1891.

(35) Diario de Cádiz, 2--V-1891,

(36) Crónica de Cádiz y su provincia, 4-V-1891.

(37) Diario de Cádiz, 3-V-1891, que lo toma de La Crónica. 
Ante la actitud de los albañiles en los demás casos, los dueños de un par de obras en las que sí se trabajaba pidieron la protección de parejas de orden público del Ayuntamiento. Lo mismo ocurrió en la fábrica de harinas de los Señores Ojeda, sita en la calle Abreu.

Sin embargo, todo esto no parecía suficiente para que se estropease una cierta imagen de anormal tranquilidad en las calles, como indica De Laigue cuando escribe, a las once treinta horas del día 1: "Les magasins ont leur aspect habituel: quelques uns seulement tiennent leurs devantures fermées mais les portes demeurent ouvertes" (38); o como también ilustra este texto:

"presentaba Cádiz un aspecto, en algunas calles, como nunca le bemos visto: en la Aduana, por ejemplo, donde de ordinario hay tanto tránsito, no se encontraba alma viviente, y los carros del tráfico no salieron aquel dia..." (39).

Pero esta calma se truncará cinco minutos má tarde de la hora fijada para el comienzo de la manifestación. Los trabajadores, descritos por el cónsul media hora antes como indolentemente sentados en los bancos de la plaza de San Antonio en cantidad aproximada a una centena, "como obedeciendo una consigna, todos los obreros se agruparon..." (40); De Laigue coincide también en la impresión de rapidez del movimiento: "un groupe...s'est brusquement formé" (41). Los manifestantes, en un número inicial de cuatrocientos según la Crónica de Cádiz, marcharon por la calle Ancha hacia su Centro en la calle Sagasta, incrementándose notablemente sus efectivos, hasta alcanzar según alguna fuente los 6.000 individuos (42), y a su paso fueron cerrándose los establecimientos, pero reuniéndose para presenciar el desfile gran cantidad de curiosos "en vista de la actitud pacífica que habían adoptado" (43).

(38) A.M.A.E.F., C.P.C., Cadix, Vol. 99, 1-V-1891.

(39) Diario de Cádiz, 5-V-1891.

(40) Crónica de Cádiz y su Provincia, 4-V-1891.

(41) A.M.A.E.F., C.P.C., Cadix, Vol. 99, 1-V-1981.

(42) BALADRON, B., Art.Cit,. p. 206., refiriéndose a El productory Kaplan,, T., Origenes sociales del anarquismo en Andalucía, Crítica. Barcelona, 1977, p. 192:

(43) Entre los que se cita al marqués de Santo Domingo, el impulsor de las fondas populares, y al que De Laigue denomina "le plus pur et le plus ardent des <dynastiques >" y uno de "les plus brillants zélateurs du regalisme...." (A.M.A.E.F., C.P.C., Cadix, Vol. 99, 27-IV-1891), a quien, según esta misma información diplomática, es fácil ver "de temps en temps, en ouverte et amicale conversation avec..." el propio Salvochea. 
El gobernador, en cuanto fue noticioso de esto, salió al frente de un destacamento de la Guardia Civil, y tras recoger a varios números más en diversos puntos de la ciudad, marchó, con un total de 120 hombres, a buscar la manifestación, que se había detenido en el Centro Obrero sólo para sacar su ya conocida bandera roja con el lema de las ocho horas. Cuando los grupos se encontraron, en la calle de La Rosa, las fuerzas del orden calaron bayoneta y acometieron a los trabajadores. Ante esto la manifestación, evidentemente, se disolvió, pero los anarquistas tendieron a ir agrupándose poco a poco en diferentes lugares, por lo que los guardias se dividieron en tres pelotones para patrullar. Esta actitud lleva a un periódico local a decir que:

"todo el mundo, incluso los obreros, elogian a la Guardia civil por la prudencia con que trató de evitar percances que bubieran podido causar días de luto á Cádiz, dada la resolución irrevocable de los obreros de celebrar manifestación pública" (44).

Opinión no compartida por todo el mundo, como demuesta nuestra fuente francesa:

"D'aprés certain bruit dont je n'ai pas contróler l'exactitude on aurait poussé la répression un peu plus loin qu'il n'était necessaire car les manifestants ne paraisaient terribles ni par leur nombre ni par leur attitude" (45).

Durante el resto del día tenemos constancia de la detención de, al menos, seis obreros, ente los que se encuentra Manuel Cerrajón Escalera, el secretario del Cento Obrero. Su traslado supuso algún percance, puesto que al ser conducido por una pareja de guardias por la calle Compañía, sus custodiadores fueron asaltados por dos sujetos "provistos de armas", que exigieron la liberación del preso. Ante esto, los agentes "tuvieron necesidad de sacar los rewolvers para no ser agredidos" (46), poniendo en fuga a sus asaltantes, que no pudieron ser identificados.

(44) Crónica de Cádiz y su provincia, 4-V-1891.

(45) A.M.A.E.F., C.P.C., Cadix, Vol. 99. 1-V-1891. Realmente a De Laigue da la impresión de no caerle muy en gracia el gobernador civil, del que dice que en esa jornada "s'est exhibé par les rues en redingote et coiffé de une espéce de casquette d'amiral".

(46) Diario de Cádiz, 2-V-1891. 
En cuanto a las reivindicaciones obreras, la prensa únicamente nos deja constancia de la consecución de las ocho horas por los marmolistas, sólo con el anuncio de su intención de iniciar la huelga si no se les concedían (47), y del aumento de salario solicitado por los empleados en la fábrica de harinas de los Señores Ojeda (48). Junto a esto, sabemos que la huelga continuó varios días en el sector de la construcción, con la presencia constante de piquetes de huelguistas. También la vigilancia policial se mantuvo varias jornadas más durante el tiempo del embarque de los obreros de la Trasatlántica (49).

Para concluir, queremos señalar la auténtica implantación que la ideología anarquista parece haber logrado, gracias a la labor proselitista efectuada en la ciudad por Salvochea, y el interesante desarrollo que igualmente daba la impresión de estar viviendo el movimiento puramente asociativo, sindical y reivindicativo desde la tan cercana fundación del Centro Obrero, en una zona en la que el obrerismo se había visto sañudamente reprimido desde, al menos, los sucesos de la Mano Negra. Renacimiento obrero surgido, precisamente, al calor de la primera celebración de la jornada del 1 de Mayo como día de reivindicación obrera, y que, como muestra de este señalable y reseñable florecimiento radical, nos ofrece la conmemoración, en forma de manifestación, de tal fecha el año siguiente, a pesar de todas las medidas tomadas por la autoridad para impedirlo, detención de los más caracterizados líderes incluida. Finalmente, sólo señalaremos la brevedad de este período de expansión, truncado por la represión subsiguiente al asalto campesino a Jerez de la Frontera, como elemento exógeno a la ciudad, y por la propia dinámica de propaganda por los hechos en la que, posiblemente, se ve inmersa la propia asociación local. Pero ése ya es asunto de otro estudio.

(47) Ibìdem.

(48) Crónica de Cádiz y su Provincia, 4-V-1891.

(49) Ibìdem. 